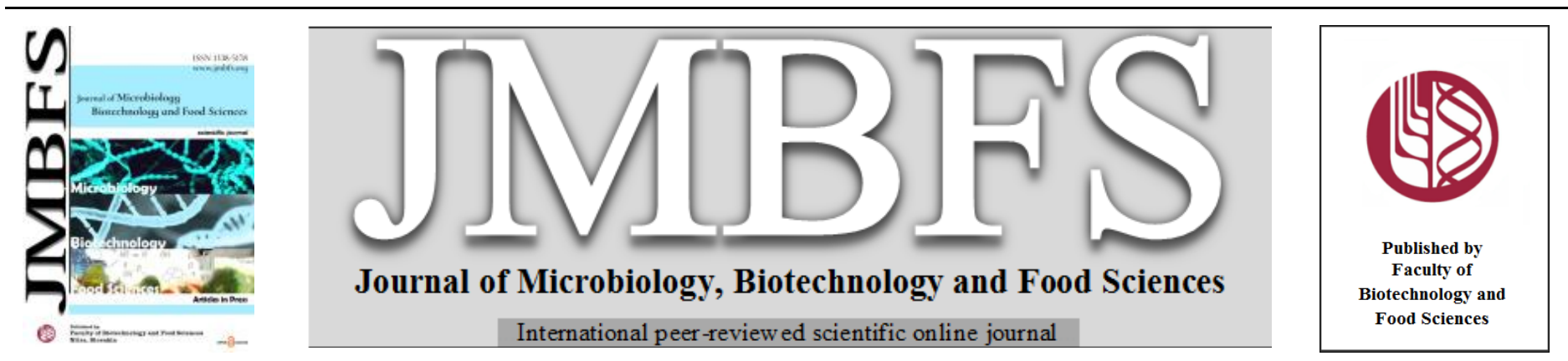

\title{
PURIFICATION POLYMERASES \\ AND ANALYSIS CATALYTIC FUNCTIONS OF RECOMBINANT INFLUENZA VIRAL
}

\author{
Khanh Tan Nguyen ${ }^{2,5}$, Hung Manh Tran ${ }^{2,5}$, Anh Tuan Trieu ${ }^{3,5}$, Van Thi Huynh Nguyen ${ }^{2,5}$, Hoang M.Nguyen ${ }^{4}$, Phu Tran Vinh Pham ${ }^{1,5 *}$ \\ Address(es): Phu Tran Vinh Pham, Ph.D. \\ ${ }^{1}$ Faculty of Medicine, Dong A University, 33 Xo Viet Nghe Tinh street, Da Nang 550000, Vietnam, phone number: (+84)-978-595-013. \\ ${ }^{2}$ Scientific Management Department, Dong A University, 33 Xo Viet Nghe Tinh street, Da Nang 550000, Vietnam. \\ ${ }^{3}$ Faculty of Food Technology, Dong A University, 33 Xo Viet Nghe Tinh street, Da Nang 550000, Vietnam. \\ ${ }^{4}$ Faculty of Chemical Engineering, the University of Da Nang-University of Science and Technology, Da Nang 550000, Vietnam. \\ ${ }^{5}$ UDA-Institute of Applied Life Sciences (UDA-IALS), Dong A University, 33 Xo Viet Nghe Tinh street, Da Nang 550000, Vietnam.
}

*Corresponding author: phuptv@ donga.edu.vn

https://doi.org/10.55251/jmbfs.4954

\section{ARTICLE INFO}

Received 28. 6. 2021

Revised 3. 10. 2021

Accepted 12. 10. 2021

Published 1. 2. 2022

Regular article

OPEN $\partial_{\text {ACCESS }}$

\begin{abstract}
Polymerase of influenza virus is made up of three subunits PB1, PB2, and PA, which are involved in viral genome transcription and replication. Purification of sufficient amounts of viral polymerase is essential to understand the catalytic function of viral polymerase. In this study, we generated a viral polymerase expression system in human embryonic kidney $293 \mathrm{~T}$ cells (293T cells). The cDNAs for RNA segments 1,2, and 3, which encode for PB2, PB1, and PA proteins, respectively, were integrated into the mammalian expression plasmids pCAGGS to simultaneously express all viral polymerase proteins in 293T cells. We purified the recombinant polymerases of human influenza virus A/PR/8/34 (H1N1) (PR8) and avian influenza virus A/Turkey/England/1969 (H3N2) (TE) using anti-FLAG M2 affinity resin. After confirming trimeric complexes, enzymatic properties of recombinant polymerases were characterized, including model viral RNA binding, in vitro transcription assays, and cap-snatching activity upon addition of cap1-70 mer vRNA as substrate. Taken together we conclude that $293 \mathrm{~T}$ cells are a suitable expression system for sufficient amount isolation of functional recombinant influenza viral polymerases with $95 \%$ of purity.
\end{abstract}

Keywords: Cap-snatching, 293T cells, transcription, purification, viral polymerase

\section{INTRODUCTION}

Influenza viruses of family Orthomixoviridae are enveloped viruses with genomes made up eight RNA segments which are negative-sense and single-stranded molecules. According to the ability of matrix (M) and nucleoprotein (NP) proteins to induce immune responses, influenza viruses are divided to four basic kinds $\mathrm{A}$ B, C, and D (Fodor et al. 2002). Among these viruses, influenza A viruses (IAVs) are further subclassified into different subtypes based on surface glycoprotein serotypes including hemagglutinin (HA) and neuraminidase (NA). To produce influenza mRNAs, polymerase (PA, PB1, and PB2) interacts with host cellular RNA polymerase II, which provides host cellular capped mRNAs becoming primers for the synthesis of newly viral mRNA. This whole procedure is called "cap snatching". In viral infected cells, PB2 recognizes the cap-1 cellular mRNA, which is cleaved by PA to generate 10-15 nucleotides of capped RNA primers. PB1 as a catalytic subunit adds nucleotides to nascent transcripts (Pflug A et al. 2017). In contrast, replication of viral genome appears through de novo synthesis without the use of capped RNA primers (Deng T et al. 2006). In the initial step of viral replication, cRNA intermediate is produced from a template vRNA and subsequently a high number of progeny vRNA is synthesized from that newly cRNA (Nagata K et al. 2008). It is reported that viral polymerase is important in the mammalian adaptation of avian IAVs (Gabriel G et al. 2008). Along to the adaptation of avian IAVs to mammals, adaptive mutations were identified in different subunits of polymerase. Surprisingly, adaptive mutations were mainly found in PB2 and PA subunits (Foeglein A et al. 2011). Therefore, understanding novel functions of viral polymerase is a key point to clarify the adaptation mechanism of avian IAVs.

Because RNA polymerase is strongly connected with vRNA in virion and its quantity is relatively low, as well as the effectiveness of reconstitution in vitro, it is still challenging to purify sufficient amounts of recombinant RNA polymerase in active form (Wood JS et al. 2007). Some systems have been created to express recombinant proteins of influenza RNA-dependent RNA polymerase. The original breakthrough was accomplished utilizing vaccinia virus as an in vivo expression system; however, due to the low amount of expressed polymerase and cytopathogenic effect of vaccinia virus plasmids, this technique is not ideal for high amount purification of viral polymerase (Fodor $\mathbf{E}$ et al. 1999). Later, two expression platforms, recombinant Baculovirus and methylotrophic yeast Pichia pastoris, were used to express three subunits and formation of viral polymerase complex (Honda A et al. 2002). Unfortunately, these coexpresison systems are suitable to sufficient amount of viral polymerase purification in active form because the purity of recombinant polymerases and the yield of purifications are quite low. Therefore, it is necessary to develop another system to get enough amount of purified viral polymerase.

The main goal of our current research is to synthesize and purify recombinant viral polymerase using human embryonic kidney 293T (293T) cells as a host strain and then to investigate enzymatic activity of purified polymerases. When we used $293 \mathrm{~T}$ cells as a expression system for human and avian influenza viral polymerases, we succeeded to purify the trimeric complex of viral polymerases. Then biochemical analysis was carried out using purified viral polymerases. We found that these viral polymerases are remained the equal viral RNA binding amount, in vitro transcription activity, and in vitro cap-snatching process. Additionally, based on molecular docking we demonstrated that cap-binding activity of PR8 viral polymerase was similar to that of TE viral polymerase.

\section{MATERIAL AND METHODS}

\section{Plasmids and cell lines}

The cDNAs encoding PB1, PB2, and PA subunits of polymerases of human influenza virus A/PR/8/34 (H1N1) (PR8) and avian influenza virus A/Turkey/England/1969 (H3N2) (TE), respectively, were cloned into pCAGGS expression vectors. 293T cells were grown in Dulbecco's Modified Eagle Medium (DMEM) plus $10 \%$ fetal bovine serum (FBS). Transfected cells were incubated at $37^{\circ} \mathrm{C}$ with $5 \%$ of $\mathrm{CO}_{2}$. 


\section{Prepare recombinant proteins of viral polymerases}

With $1 \mu \mathrm{g} / \mu$ l polyethylenimine (PEI), $2 \times 10^{6}$ of $293 \mathrm{~T}$ cells were transfected with pCAGGS plasmids integrating PA, PB1, and PB2-FLAG, as well as pHH21 vector carrying 33 nucleotides short model influenza viral genome, which was designed previously (Pham P.T.V et al. 2018). Cells were harvested after 24 hours of post transfection, sonicated on ice in $10 \mathrm{ml}$ of a buffer containing $20 \mathrm{mM}$ Tris- $\mathrm{HCl}$ (pH 7.9), $0.1 \%$ Nonidet P-40 (NP-40), $100 \mathrm{mM} \mathrm{NaCl}$ and then centrifuged at $12,000 \mathrm{x}$ $\mathrm{g}$ for 20 minutes at $4^{\circ} \mathrm{C}$. Cell lysates were soaked for $1 \mathrm{~h}$ at $4^{0} \mathrm{C}$ with $100 \mu \mathrm{l}$ of antiFLAG M2 affinity beads (Sigma-Aldrich). Viral polymerases were eluted using $100 \mu \mathrm{l}$ of an elution buffer comprising $20 \mathrm{mM}$ Tris- $\mathrm{HCl}$ (pH 7.9), $0.1 \mathrm{mg} / \mathrm{ml}$ FLAG peptide (Sigma-Aldrich), $0.1 \% \mathrm{NP}-40$, and $100 \mathrm{mM} \mathrm{NaCl}$ after washing with 300 $\mu 1$ of a buffer containing $20 \mathrm{mM}$ Tris- $\mathrm{HCl}$ (pH 7.9), $0.5 \% \mathrm{NP}-40$, and $150 \mathrm{mM}$ $\mathrm{NaCl}$. The eluted polymerases were collected and kept at $-80^{\circ} \mathrm{C}$ until needed.

\section{Immunoblotting of polymerase complexes}

The presence of $\mathrm{PB} 1, \mathrm{~PB} 2$, and $\mathrm{PA}$ in recombinant viral polymerases were confirmed by Western blot experiment. Sufficient amounts of purified polymerases were run through a $7.5 \%$ SDS-PAGE gel before being transferred to polyvinylidene fluoride (PVDF) blotting membrane. The membrane was treated with anti-PA, anti-PB1 as well as anti-PB2 antibodies to detect relevant each subunit of polymerases.

\section{Primer extension of vRNA promoter}

To identify vRNA promoter binding activity, the isolated polymerases were first incubated with $40 \mathrm{ng} / \mu \mathrm{l}$ Proteinase $\mathrm{K}$ in a buffer consisting $100 \mathrm{mM}$ Tris- $\mathrm{HCl}(\mathrm{pH}$ 7.9), $25 \mathrm{mM}$ EDTA, $0.5 \% \mathrm{SDS}$, and $100 \mathrm{mM} \mathrm{NaCl}$ for $30 \mathrm{~min}$ at $37^{\circ} \mathrm{C}$. The short model viral genome was then extracted and precipitated using phenol-chloroform solution and ethanol, respectively. Purified vRNAs were submitted to primer extension experiment using a relevant primer as previously described (Pham P.T.V et al. 2018), that was labeled at the 5 ' end with $\left[\gamma^{32} \mathrm{P}\right]$ ATP (Perkin Elmer) under the catalysis of T4 polynucleotide kinase as introduced previously (Kawaguchi A et al. 2005). After purifying by phenol-chloroform extraction and ethanol precipitation, the products were applied to a $12 \%$ PAGE gel adding $8 \mathrm{M}$ urea and autoradiographed using a Typhoon scanner (GE Healthcare)

\section{In vitro transcription assays}

Primer-independent RNA synthesis in vitro was carried out in a $20 \mu$ reaction volume comprising relevant amounts of recombinant polymerases, $50 \mathrm{mM}$ HEPES sodium hydroxide ( $\mathrm{pH} 7.9$ ), $1.5 \mathrm{mM}$ DTT, $100 \mathrm{mM} \mathrm{KCl}, 5 \mathrm{mM} \mathrm{MgCl} 2,8 \mathrm{U}$ of RNase inhibitor, $0.5 \mathrm{mM}$ for each nucleotide ATP, UTP, and CTP, $25 \mu \mathrm{M}$ GTP, $0.7 \mu \mathrm{M}\left[\alpha{ }^{32} \mathrm{P}\right] \mathrm{GTP}(3000 \mathrm{Ci} / \mathrm{mmol})$ (Perkin Elmer), and $0.25 \mathrm{mM}$ ApG. In vitro primer-dependent RNA synthesis was carried out under the identical circumstances, with the exception that ApG was substituted by $200 \mathrm{ng}$ beta-globin mRNA. Reactions were carried out for $1 \mathrm{~h}$ at $30^{\circ} \mathrm{C}$ before being eventuated in phenol-chloroform extraction and ethanol precipitation. Transcription products were heated for $2 \mathrm{~min}$ at $95^{\circ} \mathrm{C}$ in the presence of formamide dyes, loaded onto an $8 \mathrm{M}$ urea $15 \%$ PAGE gel in Tris-Borate-EDTA buffer, and finally identified by autoradiography.

\section{Cap-snatching reaction in vitro}

The 70 nucleotides RNA previously synthesized (Pham P.T.V et al. 2018) was incubated in a solution consisting of $50 \mathrm{mM}$ Tris hydrochloride $(\mathrm{pH} 7.9), 75 \mu \mathrm{M}$ S-adenosylmethionine (SAM; New England Biolabs), $2 \mathrm{mM} \mathrm{MgCl}, 2 \mathrm{mM}$ DTT $8 \mathrm{U}$ of RNase inhibitor, $10 \mu \mathrm{Ci}$ of $\left[\alpha^{-32} \mathrm{P}\right] \mathrm{GTP}(3000 \mathrm{Ci} / \mathrm{mmol})$ under the catalysis of two vaccinia capping enzymes D1/D12 and VP39 for $1 \mathrm{~h}$ at $37^{\circ} \mathrm{C}$ as previously reported (Wakai C et al. 2011). In a $20 \mu 1$ reaction volume comprising $50 \mathrm{mM}$ HEPES-NaOH (pH 7.9), $50 \mathrm{mM} \mathrm{KCl,} 1.5 \mathrm{mM}$ DTT, $5 \mathrm{mM} \mathrm{MgCl}$, 8 U of RNase inhibitor, and 5 fmol of cap1-RNA-70mer labeled by $\left[\alpha-{ }^{32} \mathrm{P}\right]$ radioisotope $(800$ $\mathrm{cpm} / \mathrm{fmol}$ ) with $1 \mathrm{fmol}, 2 \mathrm{fmol}$, and 4 fmol of recombinant polymerases, respectively, the endonuclease activity of viral polymerase was determined. After 1 hour of incubation at $30^{\circ} \mathrm{C}$, the digested RNA products were extracted and precipitated using phenol-chloroform solution and ethanol, respectively, separated on an $8 \mathrm{M}$ urea $15 \%$ PAGE gel, and observed using autoradiography.

\section{Structures of Protein and ligand preparation}

The crystal structures of PB2 subunit cap binding domains of two influenza virus strains A/PR/8/34 (H1N1) (PDB ID: 4ENF) (Liu Y et al. 2013) and A/duck/Shantou/4610/2003 (H5N1) (PDB ID: 4CB6) (Pflug A et al. 2018) were available from Protein Data Bank of Research Collaboratory for Structura Bioinformatics. Based on the alignment from Expasy Server (https://swissmodel.expasy.org), PB2 cap-binding domain of Influenza $\mathrm{A} /$ duck/Shantou/4610/2003 (H5N1) is homologous to that of A/Turkey/England/1969 (H3N2) with $98.16 \%$ overall sequence identity. Next, the PB2 cap-binding domain crystal structures were processed by removing existing ligand, water molecules. Using the Autodock tools version 1.5.6, polar hydrogens and charges of Kollman were then added to the protein. Finally, the macromolecule was exported into a dockable pdbqt file format for molecular docking.

3D structures of $\mathrm{m}^{7} \mathrm{GTP}$ were prepared by MarvinSketch (ChemAxon, USA). In the last step, the ligands were converted to dockable pdbqt format utilizing Open babel.

\section{Molecular docking}

Molecular interaction of $\mathrm{m}^{7} \mathrm{GTP}$ and two target proteins was carried out using AutoDock Vina. The active site of protein was predicted from CASTp $3.0 \mathrm{web}$ server (Computer Atlas of Surface Topography of Proteins). The grid boxes that cover the active sites of cap-binding domains of influenza viruses A/PR/8/34 and A/duck/Shantou/4610/2003 were generated with following parameters: center_x:y:z $=22.8: 52.5: 33.5$, size_x:y:z= 25:25:25 and center_x:y:z = 10.137:9.5:41.5, size_x:y:z $=25: 25: 25$, respectively. Docking scores are reported in $\mathrm{kcal} / \mathrm{mol}$. Finally, the molecular interactions between proteins and ligand were visualized by Discovery Studio Visualizer.

\section{RESULTS}

\section{Purification of recombinant viral polymerases}

Recombinant viral polymerases containing a 33-mer model virus genome were purified using anti-FLAG M2 Magnetic Beads from 293T cells expressing PA PB1 and PB2-FLAG, which were generated from PR8 or TE virus strain. The purified proteins were separated on a SDS-PAGE gel and stained with Coomassie Brilliant Blue (CBB) solution, which revealed that the purity of recombinan polymerases was more than $95 \%$ according to ImageJ software analysis [Fig. 1A]. Furthermore, we discovered that PR 8 and TE viral polymerases had identical amounts of each subunit based on western blot experiment with antibodies of antiPA, anti-PB1, and anti-PB2 [Fig. 1B], suggesting that trimeric complex of influenza polymerases is successfully formed in $293 \mathrm{~T}$ cells

It has been confirmed that the promoter sequence is necessary for both viral RNA production and cap-snatching activity of influenza polymerase (Leahy MB et al. 2002). vRNA co-isolated with recombinant polymerase complex was used in the extension experiments of primer in the presence of a ${ }^{32} \mathrm{P}$-labeled specific primer for the model viral genome to determine the promoter binding ability of influenza viral polymerases. The result showed that the proportion of vRNA interacted to viral polymerase of TE was similar to that of PR8 [Fig. 1C], indicating that these viral polymerases have enough promoter binding activity after purifying from 293 T cells.

\section{In vitro transcription activity of recombinant polymerases}

ApG-primed RNA synthesis in vitro was carried out to investigate the viral RNA synthesis ability of recombinant viral polymerase. The activity of viral RNA production without the cap-snatching reaction was examined using ApG dinucleotide primer, which is complementary to the 3' end of viral promoter sequence. Both purified polymerase complexes of PR8 and TE demonstrated the ability of ApG-primed RNA synthesis triggered by v33 nucleotide template [Fig. 2A]. This dícovery indicated that recombinant polymerases purified from $293 \mathrm{~T}$ cells had intrinsic RNA polymerization activity.

In viral infected cells, during the transcription, first PB2 interacts to the 5'-end cap host pre-mRNA. Then PA digests this mRNA by endonuclease activity to generate capped RNA primer (around 10-15 nt) for the viral transcription. This process is named cap-snatching. Finally, in the presence of nucleotides, PB1 will elongate the capped RNA primer to synthesize new viral mRNA. Transcription activity of PR8 and TE recombinant polymerase was then investigated using beta-globin mRNA as a cap donor. Both viral polymerases produced transcription products [Fig. 2B]. Taken together, we conclude that recombinant polymerases purified from 293 T cells carry the ability to produce RNA based on priming of ApG or capped RNA, that are markers for the catalytic of polymerase transcription activity.

\section{Cap-snatching activity of recombinant viral polymerases}

The cap-snatching activity of polymerase complexes isolated from $293 \mathrm{~T}$ cells was next investigated by incubating these polymerases with cap1 RNA-70mer labeled $\left[\alpha-{ }^{32} \mathrm{P}\right]$ radioisotope. The capped RNA substrate was digested to produce different RNA pieces of 10-15 nt-long in length [Fig. 3].

In the occurence of v33 nucleotide model viral genome, endonuclease activity was detected in both PR8 and TE recombinant polymerases purified from $293 \mathrm{~T}$ cells. This result supports a proposed statement that the vRNA atcs as an effective activator for the association of influenza viral polymerase endonuclease to capped RNA subtrate. All together we reported that the trimeric polymerase complex containing vRNA promoter sequence has the cap-snatching activity of purifying from expression system $293 \mathrm{~T}$ cells. 


\section{Comparisons of Cap-binding activity}

Molecular docking was performed to identify the cap binding activity of influenza polymerase complexes [Fig. 4]. Docking scores showed that PB2 cap-binding domain of TE had similar binding affinity to that of PR8 (approximately $-7,2$ $\mathrm{kcal} / \mathrm{mol}$ ). This suggest that the expresison system may not have effect on the binding ability of influenza polymerase to capped RNA. Taken together, these results indicate that avian influenza polymerase had weaker cap-snatching ability than human influenza polymerse maybe because PA subunit was impaired the activity of endonuclease.
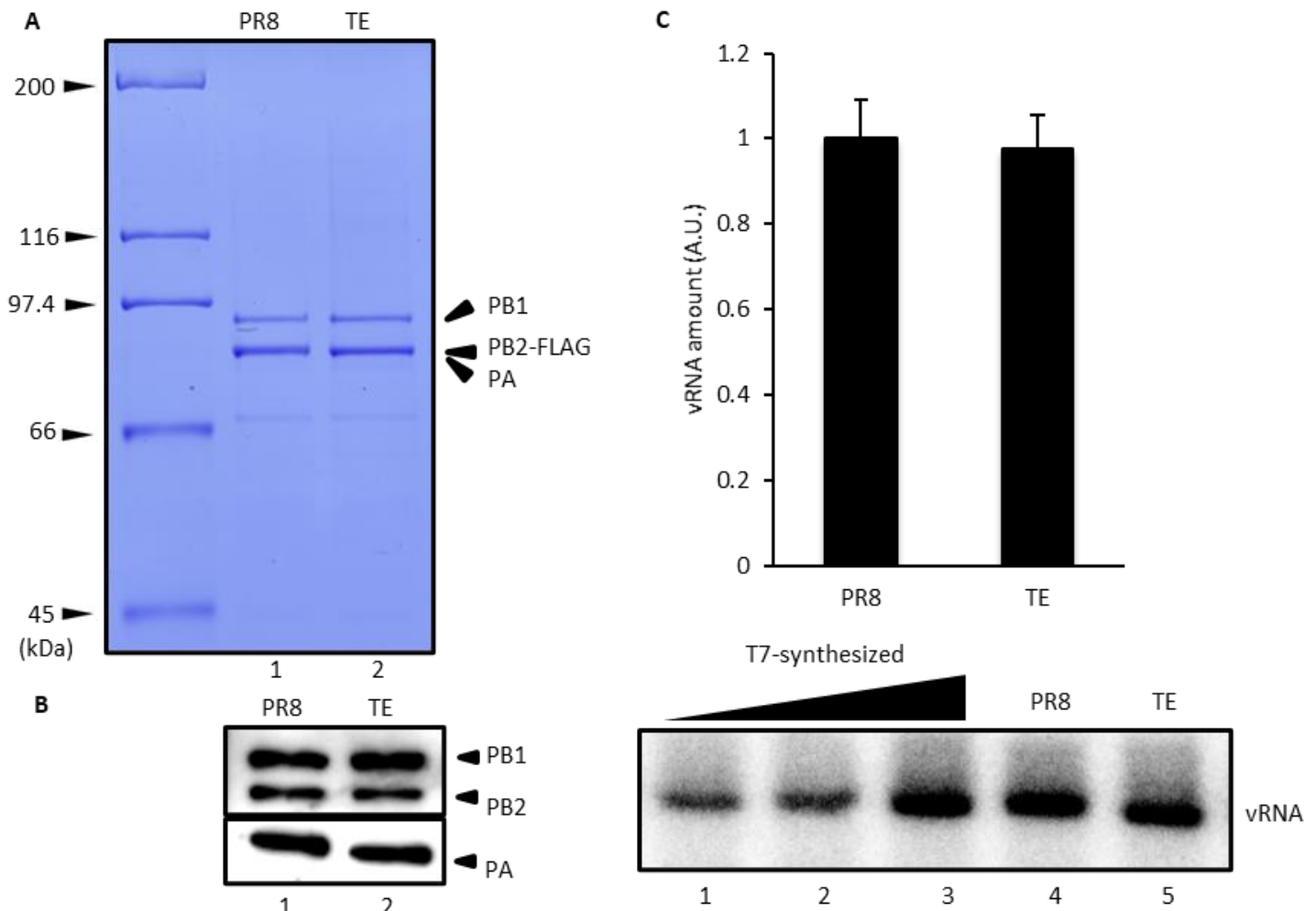

Figure 1 Isolation of recombinant polymerase complexes carrying small model of viral genome. (A) CBB coloring was used to visualize purified polymerases separated by $7.5 \%$ SDS-PAGE. (B) Antibodies against PA, PB1, and PB2 were used in Western blot experiments. (C) Primer extension tests were performed on vRNA produced from $100 \mathrm{ng}$ of each recombinant polymerases using a specific primer for the model viral genome. ImageJ software was used to quantify the intensity of bands, and three independent experiments were carried out.

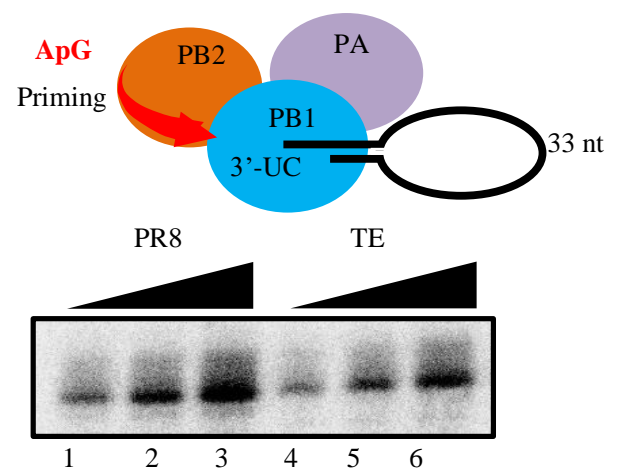

B

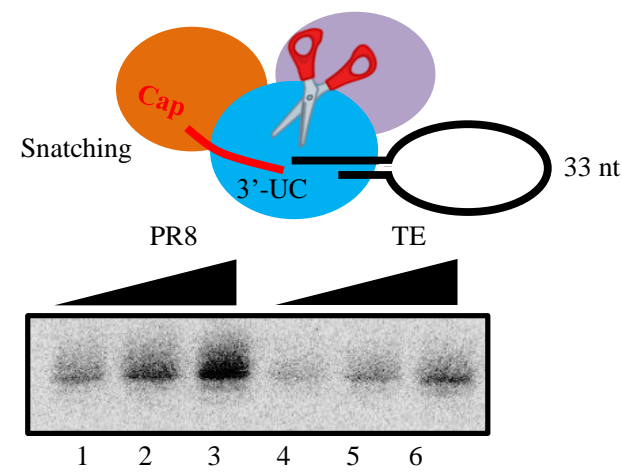

Figure 2 Viral RNA synthesis activity in vitro of purified viral polymerases. (A) ApG-primed RNA production.The in vitro transcription of ApG-primed RNA in dose dependency by viral polymerases incubated with ATP/CTP/UTP and ${ }^{32} \mathrm{P}$-labeled GTP and ApG. (B) $\beta$-globin mRNA as a capped donor. The transcription ability in vitro of recombinant polymerases was investigated in the presence of a capped structure derived from $\beta$-globin mRNAs. In the addition of nucleotides, the cleavage products from beta globin mRNA were extended into transcription products under the catalysis of viral polymerase. PR8 (lanes 1-3) and TE (lanes 4-6). Autoradiography was used to identify transcription products, which were examined using a $15 \%$ PAGE gel plus $8 \mathrm{M}$ urea. 


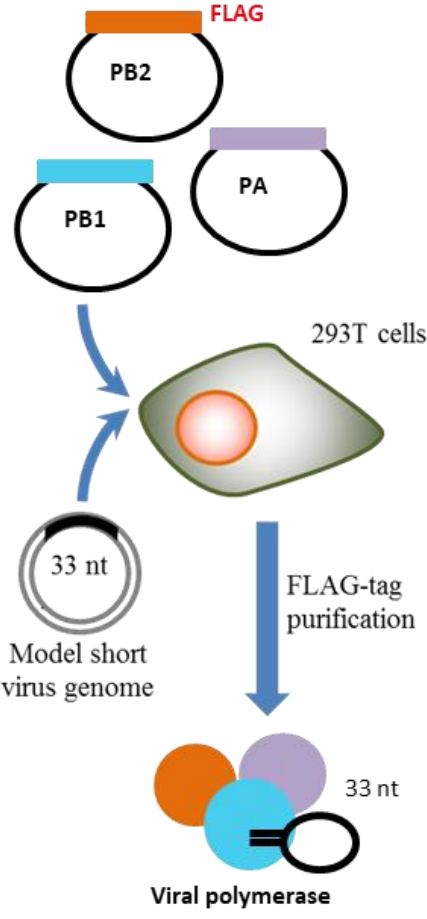

Figure 5 Expression scheme of viral polymerase. The recombinant polymerase formed in HEK 293T cells after co-transfection of three viral polymerase expression plasmids containing encoded genes for PB1, PB2, and PA subunit in the presence of model short viral genome (vRNA 33mer). After 24h of transfection, viral polymerase was purified by using FLAG affinity beads.
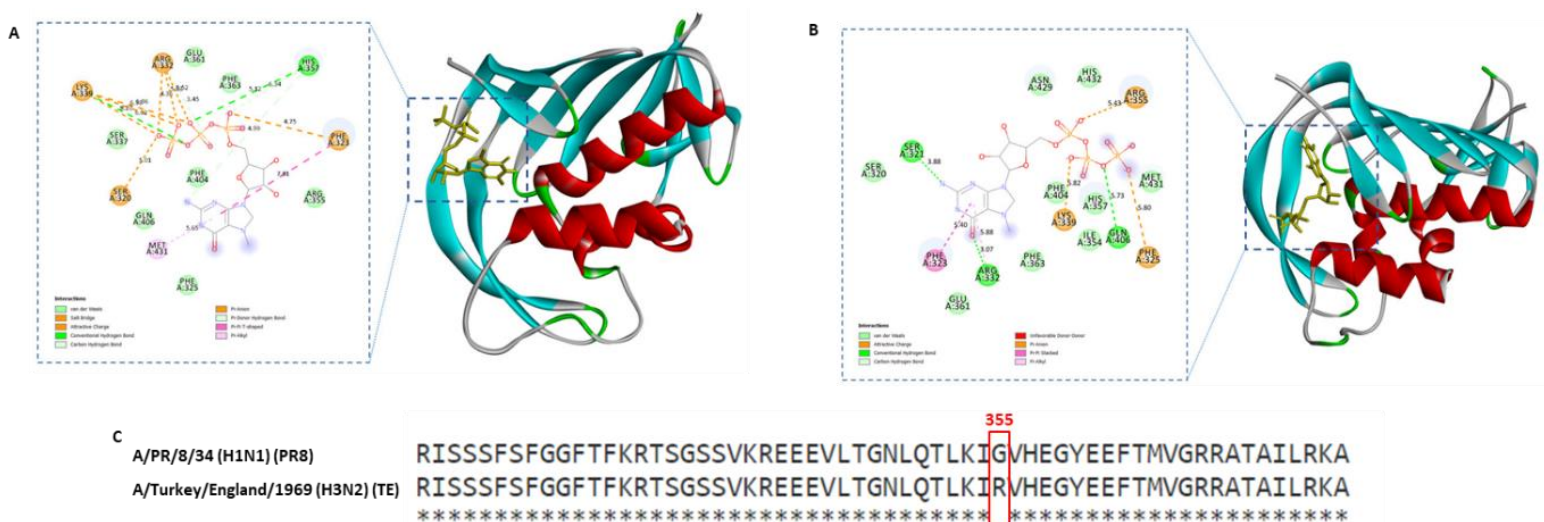

\section{5}

RISSSFSFGGFTFKRTSGSSVKREEEVLTGNLOTLKIGVHEGYEEFTMVGRRATAILRKA RISSSFSFGGFTFKRTSGSSVKREEEVLTGNLQTLKIRNHEGYEEFTMVGRRATAILRKA ****************************************ׁ***********************

397

A/PR/8/34(H1N1)(PR8) TRRLIQLIVSGRDEQSIAEAIIVAMVFSQEDCMIKAVRGDLNFVNRANQRLNPMHQLLRH A/Turkey/England/1969 (H3N2) (TE) TRRLIQLIVSGRDEQSIAEAVIVAMVFSQEDCMIKAVRGDLNFVNRANQRLNPMHQLLRH $* * * * * * * * * * * * * * * * * * * * \sqcup * * * * * * * * * * * * * * * * * * * * * * * * * * * * * * * * * * * * * * * *$

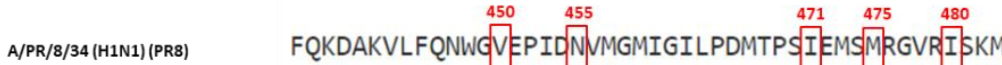
A/Turkey/England/1969 (H3N2) (TE) FQKDAKVLFQNWGIEPIDDVMGMIGILPDMTPSTEMSLRGVRVSKM

Figure 4 Comparison of cap-binding regions on PB2 subunits. (A) Human influenza A/PR/8/34 (H1N1) (PR8) bound to ${ }^{7} \mathrm{GTP}$ (yellow) and (B) Avian influenza A/Turkey/England/1969 (H3N2) (TE) bound to $\mathrm{m}^{7}$ GTP. (C) Sequence alignment of PB2 cap-binding domains. Interacting residues are similar chemical properties between PR8 and TE. Residue numbering is according to PB2 subunit sequence.

\section{DISCUSSION AND CONCLUSION}

Purified RNA polymerase is critical for in vitro study of replication and transcription process of influenza virus in infected cells. However, contaminations of cellular oligonucleotides as primers for transcription as well as contaminations of host cell polymerases and nucleases obstruct the activity of viral polymerase on RNA synthesis. The initial achievement of recombinant polymerase expression was obtained by utilizing a vector-based vaccinia virus (Fodor $\mathbf{E}$ et al. 1999) Unfortunately, this process cannot be used to purify a large amount of recombinan polymerase for in vitro investigation. Accordingly, other two expression systems of influenza viral polymerase, methylotrophic yeast Pichia pastoris and Baculovirus system, were developed to obtain a higher productivity (Honda A $\boldsymbol{e t}$ al. 2002); however, it was difficult to eliminate the contamination of host cell nucleases from influenza polymerase. In this study, we performed a method of simultaneous expression of three subunits of viral polymerase in 293T cell line
[Fig. 5]. The assembled polymerase complex contained all these proteins providing the premise three subunits are present to make up one molecule of the core viral polymerase complex.

Polymerase of influenza virus is the most crucial factor in identifying the pathogenicity of virus and the specificity of host cells. By expressing intact forms of two species of influenza polymerase in $293 \mathrm{~T}$ cells, we discovered the production of recombinant polymerases in trimeric form (PB2-PB1-PA) by expressing complete polymerase complexes of two different influenza strains in 293T cells (Pflug A et al. 2017). As predicted from this assembly approach, we were able to isolate viral polymerases [Fig. 1] and apply them to in vitro experiment to analyze the catalytic abilities. The interaction between viral polymerases and vRNA promoter could activate the functions of influenza polymerase (Nagata $\mathbf{K}$ et al. 2008). All of the known functions of influenza virus in transcription are carried out by viral polymerase, including RNA synthesis directed by capped RNA primers [Fig. 2A], polyadenylation of progeny RNAs [Fig. 2B], and cap cleavage activity 
[Fig. 3]. This finding agrees with the observation in other expression systems for influenza polymerase (Honda A et al. 2002).

In this work, we established 293T cells expression approach to express influenza polymerase simultaneously. Because trimeric complexes were produced at considerable amounts in $293 \mathrm{~T}$ cells and furthermore the purified polymerases were accumulated into functional proteins [Fig. 1A], the results were highly remarkable. Western blot experiment indicated that three subunits of polymerases, PA, PB1, and PB2, were strongly produced in 293T cells, and soluble polymerases were remained in the lysates of infected cells [Fig. 1B]. It has been addressed that three subunits polymerase are necessary for the beginning of the performance of RNA synthesis in vitro (Gabriel G et al. 2008). The isolated polymerase complexes of PR8 and TE influenza strains were used to examine the catalytic ability for in vitro RNA synthesis reaction. The polymerase complexes containing model viral genome exhibited RNA synthesis activity [Fig. 2]. The enzymatic properties of recombinant polymerases show the similar ability as the isolated or reconstituted influenza virus RNA: (i) without promoter sequence, polymerase complex is unable to activate the process of RNA synthesis [Fig. 2A] (ii) capped RNA primers are able to initiate the synthesis of model template-dependent RNA [Fig. 2B] (Foeglein A et al. 2011). These characteristics of enzyme reaction are typical of transcriptase. Thus, we concluded that 293T cells expression system is suitable for sufficient amount purification of functional recombinant polymerases from avian as well as human influenza viruses.

Acknowledgments: Dong A University, Vietnam and University of Tsukuba, Japan had provided funding and facilities for this study of Phu Tran Vinh Pham.

\section{REFERENCES}

Deng, T., Engelhardt, O.G., Thoma,s B., Akoulitchev, A.V., Brownlee, G.G., Fodor, E. (2006). Role of ran binding protein 5 in nuclear import and assembly of the influenza virus RNA polymerase complex. Journal of Virology. 80(24):119119. https://doi.org/10.1128/JVI.01565-06

Fodor, E., Brownlee, G.G. (2002). Influenza virus replication. Perspectives in Medical Virology. 7:1-29. https://doi.org/10.1016/S0168-7069(02)07002-7.

Fodor, E., Devenish, L., Engelhardt, O.G., Palese, P., Brownlee, G.G., GarciaSastre, A. (1999). Rescue of influenza A virus from recombinant DNA. Journal of Virology. 73(11):9679-9682. https://doi.org/10.1128/JVI.73.11.9679-9682.1999

Foeglein, A., Loucaides, E.M., Mura, M., Wise, H.M., Barclay, W.S., Digard P (2011). Influence of PB2 host-range determinants on the intranuclear mobility of the influenza A virus polymerase. Journal of General Virology. 92(7):1650-61. https://doi.org/10.1099/vir.0.031492-0

Gabriel, G., Herwig, A., Klenk, H.D. (2008). Interaction of Polymerase Subunit PB2 and NP with Importin $\alpha 1$ Is a Determinant of Host Range of Influenza A Virus. PLoS Pathogens. 4(2):e11. https://doi.org/10.1371/journal.ppat.0040011

Honda, A., Mizumoto, K., Ishihama, A. (2002). Minimum molecular architectures for transcription and replication of the influenza virus. Proceedings of the National $\begin{array}{lllll}\text { Academy of } & \text { Sciences. } & 99 & \text { (20) 13166-13171. }\end{array}$ https://doi.org/10.1073/pnas.152456799

Kawaguchi, A., Naito, T., Nagata, K. (2005). Involvement of influenza virus PA subunit in assembly of functional RNA polymerase complexes. Journal of Virology. 79(2):732-44. https://doi.org/10.1128/JVI.79.2.732-744.2005

Leahy, M.B., Zecchin, G., Brownlee, G.G. (2002). Differential activation of influenza A virus endonuclease activity is dependent on multiple sequence differences between the virion RNA and cRNA promoters. Journal of Virology. 76:2019-2023. https://doi.org/10.1128/JVI.76.4.2019-2023.2002

Liu, Y., Qin, K., Meng, G., Zhang, J., Zhou, J., Zhao, G., Luo, M., Zheng, X. (2013). Structural and functional characterization of K339T substitution identified in the PB2 subunit cap-binding pocket of influenza A virus. Journal of Biological Chemistry 288(16):11013-11023. https://doi.org/10.1074/jbc.M112.392878

Nagata, K., Kawaguchi, A., Naito, T. (2008). Host factors for replication and transcription of the influenza virus genome. Reviews in Medical Virology. 18(4):247-60. https://doi.org/10.1002/rmv.575

Pflug, A., Lukarska, M., Resa-Infante, P., Reich, S., Cusack, S. (2017). Structural insights into RNA synthesis by the influenza virus transcription replication machine. Virus Research. 234:103-117. https://doi.org/10.1016/j.virusres.2017.01.013

Pflug, A., Gaudon, S., Resa-Infante, P., Lethier, M., Reich, S., Schulze, W.M., Cusack, S. (2018). Capped RNA primer binding to influenza polymerase and implications for the mechanism of cap-binding inhibitors. Nucleic Acids Research 46(2):956-971. https://doi.org/10.1093/nar/gkx1210

Pham, P.T.V., Turan, K., Nagata, K., Kawaguchi, A. (2018). Biochemical characterization of avian influenza viral polymerase containing PA or PB2 subunit from human influenza A virus. Microbes and Infection. 20(6):353-359. https://doi.org/10.1016/j.micinf.2018.04.003

Tong, S., Zhu, X., Li, Y., Shi, M., Zhang, J., Bourgeois, M., Yang, H., Chen, X. Recuenco, S., Gomez, J., Chen, L., Johnson, A., Tao, Y., Dreyfus, C., Yu, W. McBride, R., Carney, P.J., Gilbert, A.T., Chang, J., Guo, Z., Davis, C.T., Paulson, J.C., Stevens, J., Rupprecht, C.E., Holmes, E.C., Wilson, E.A., Donis, R.O. (2013). New world bats harbor diverse influenza A viruses. PLoS Pathogens. 9(10):e1003657. https://doi.org/10.1371/journal.ppat.1003657
Wakai, C., Iwama, M., Mizumoto, K., Nagata, K. (2011). Recognition of cap structure by influenza B virus RNA polymerase is less dependent on the methyl residue than recognition by influenza A virus polymerase. Journal of Virology. 85(15): 7504-12. https://doi.org/10.1128/JVI.02375-10

Wood, J.S., Robertson, J.S. (2007). Reference viruses for seasonal and pandemic influenza vaccine preparation. Influenza Other Respiratory Viruses. 1:5-9. https://doi.org/10.1111/j.1750-2659.2006.00003.x 